\title{
O PROGRAMA TERRITÓRIOS DA CIDADANIA: AÇÕES E PARTICIPAÇÃO SOCIAL NO PONTAL DO PARANAPANEMA-SP
}

\author{
Fernando Amorim ROSA ${ }^{1}$ \\ Darlene Aparecida de Oliveira FERREIRA²
}

\begin{abstract}
Resumo
A abordagem territorial ganha espaço na agenda das políticas para o desenvolvimento rural no Brasil a partir da criação da Secretaria de Desenvolvimento Territorial (SDT), no ano de 2003. Sob a coordenação desta Secretaria, vinculada ao Ministério do Desenvolvimento Agrário (MDA), é criado o Programa Nacional de Desenvolvimento Sustentável de Territórios Rurais (PRONAT), por meio do qual são implementados os Territórios Rurais onde se projetam as intervenções estatais destinadas, sobretudo, a prover as infraestruturas e serviços de apoio ao desenvolvimento de cadeias produtivas agropecuárias, conferindo forte orientação setorial ao Programa. Visando superar tal orientação, numa proposta de articulação interministerial que objetiva a melhoria das condições de vida, de acesso a bens e serviços públicos e a oportunidades de inclusão social e econômica às populações que vivem no interior do país, é lançado, no ano de 2008, o Programa Territórios da Cidadania (PTC). O presente estudo buscou compreender como se dá a materialização da política de desenvolvimento territorial do governo federal no Território da Cidadania do Pontal do Paranapanema, sobretudo no que diz respeito à participação social no Colegiado de Desenvolvimento Territorial e a orientação e resultados das ações do Programa.
\end{abstract}

Palavras-chave: Desenvolvimento territorial. Desenvolvimento rural. Território. Espaços rurais. Participação.

\section{Abstract \\ Citizenship territories program: actions and social participation in Portal Paranapanema-SP}

The territorial approach has gained importance in the rural politics for the development agenda since the creation of the Territorial Development Secretary (SDT), in 2003 within the Ministry of Agrarian Development. From the SDT it is formulated the National Program for the Sustainable Development of Rural Territories (PRONAT), through which the Rural Territories are implemented. It is in the Rural Territories that the state interventions are projected with the aim of providing the infrastructures and services to support the development of agricultural productive chains. This has given a strong sector orientation to the Program. The Citizenship Territories Program (CTP) is launched in 2008 looking to overcome the sectorial orientation through a proposal of inter-ministerial articulation aiming the improvement of life conditions, access to public goods and services, and opportunities for social and economic inclusion for people living in rural areas. This research intended to show how federal government territorial development politics are implanted in the Citizenship Territories of the Portal Paranapanema; mainly concerning the social participation in the Territorial Development Collegiate, as well as to orientate and show results of the Program actions.

Key words: Territorial development. Rural development. Territory. Rural spaces. Participation.

\footnotetext{
1 Fundação Instituto de Terras do Estado de São Paulo "José Gomes da Silva" - ITESP. E-mail: f.amorim_rosa@hotmail.com

2 Universidade Estadual Paulista "Júlio de Mesquita Filho" - UNESP, campus de Rio Claro - SP. E-mail: darlene-ferreira@uol.com.br
} 


\section{INTRODUÇÃO}

O presente trabalho deriva de pesquisa que buscou analisar o movimento que na América Latina, sobretudo nas duas últimas décadas, parece ter adotado o território como panaceia para todas as questões relacionadas ao desenvolvimento, importando para o continente uma concepção onde a categoria, por meio de uma intervenção estatal responsável por dotá-la das institucionalidades necessárias para animar e sensibilizar as forças endógenas, responderia como escala ideal, através da qual se solucionariam os problemas relacionados à pobreza e à desigualdade social.

Sob esta compreensão, o território é apropriado pelo chamado desenvolvimento territorial como o lócus ideal para implementação de ações, dotado de relações de identidade, proximidade, reciprocidade e cooperação entre os denominados atores sociais, que se constituem em um trunfo, um potencial a ser explorado, capaz de garantir a estes espaços vantagens comparativas que impulsionariam seu desenvolvimento e, nesta lógica, consequentes melhorias às vidas das pessoas que neles habitam.

Esta concepção pressupõe um território harmonizado, ambiente de consensos, livre de quaisquer conflitos ou contradições, plataforma à espera de que nele os diferentes grupos sociais se articulem e dialoguem em torno da construção coletiva de um projeto de futuro compartilhado.

Sob esta ótica, o território tem ocultadas suas contradições, conflitos e relações de poder inerentes. Desconsidera-se, assim, que é produto de uma construção social histórica, coletiva e conflituosa. Os conflitos, nesta interpretação, são reduzidos a divergências entre diferentes grupos sociais capazes de chegar a consensos em torno de interesses comuns, e não compreendidos como conflitos entre classes sociais antagônicas.

Com base nestas observações, procurou-se analisar o contexto em que as chamadas políticas territoriais surgem no cenário europeu dos anos 1990 e como a abordagem territorial é transposta à América Latina e incorporada à agenda das políticas de desenvolvimento dos espaços rurais no Brasil, sobretudo a partir do ano de 2003, sob forte orientação de organismos internacionais como o Banco Mundial, a Organização para Cooperação e Desenvolvimento Econômico (OCDE), a Organização das Nações Unidas para Agricultura e Alimentação (FAO), o Instituto Interamericano de Cooperação Agrícola (IICA), entre outros.

No ano de 2003, é criada, vinculada à estrutura do, atualmente extinto, Ministério do Desenvolvimento Agrária (MDA), a Secretaria de Desenvolvimento Territorial (SDT) que, a partir de então, passa a coordenar as políticas de desenvolvimento territorial no país. No mesmo ano, o governo federal lança o Programa Nacional de Desenvolvimento Sustentável de Territórios Rurais, o PRONAT. O Programa implementa uma nova institucionalidade para a intervenção estatal, o Território. A partir da criação do PRONAT inicia-se um processo de institucionalização de Territórios Rurais (TRs) em todo o país. Com isso, inaugura-se nova forma de intervenção e alocação de recursos - especialmente os oriundos da, agora autonomizada, vertente Infraestrutura e Serviços do Programa Nacional de Fortalecimento da Agricultura Familiar (PRONAF), o PROINF - que passam a ser operacionalizados na escala intermunicipal, sob gestão social dos recém formados Colegiados de Desenvolvimento Territorial, os quais reúnem diversos representantes da sociedade civil e dos poderes públicos dos vários municípios agrupados nos, assim denominados, Territórios Rurais. Conforme veremos no decorrer do trabalho, esta mudança no PRONAF Infraestrutura e Serviços, rebatizado de "Apoio a Projetos de Infraestrutura e Serviços em Territórios Rurais" (PROINF), serviu à redução do poder das oligarquias locais sobre projetos e destinação de recursos. 
O PRONAT evolui, incorporando ao longo dos anos mais espaços rurais e institucionalizando-os como Territórios Rurais. Embora tenha havido significativo avanço com a mudança na escala de gestão do PROINF, o PRONAT ainda apresentava forte orientação setorial, executando ações, predominantemente, voltadas ao desenvolvimento rural, baseadas no apoio aos interesses econômicos da agricultura familiar e no provimento de infraestruturas e serviços destinados ao desenvolvimento de cadeias produtivas agropecuárias. Ficavam relegadas dimensões como educação, cultura, saúde, meio ambiente e outras, tidas como fundamentais à superação da pobreza e da desigualdade social e regional.

Visando superar tal lógica setorial de destinação de recursos e oferta de serviços públicos do PRONAT, buscando uma articulação interministerial que possibilitasse o enfrentamento da pobreza rural e a universalização de programas que garantissem o atendimento de necessidades básicas das populações no interior do país, é instituído, no ano de 2008, o Programa Territórios da Cidadania (PTC).

O Programa, que articulava, inicialmente, dezenove ministérios (número ampliado para vinte e dois, posteriormente), passa a incorporar, já no ano de seu lançamento, sessenta Territórios de maior concentração de pobreza rural e menor dinamismo econômico dentre os cento e sessenta e quatro Território Rurais homologados. O número de Territórios incorporados passa, no ano de 2009, a cento e vinte, agora denominados Territórios da Cidadania.

De acordo com informações do extinto MDA (2009), o PTC abrange 1.852 municípios, totalizando uma população de 13,1 milhões de pessoas, aproximadamente $46 \%$ da população rural total do país ${ }^{3}$.

Frente a abrangência do Programa e dos objetivos propostos, buscamos analisar como são operacionalizadas as suas ações, como se dá a participação social no espaço do Colegiado Territorial e, remetendo à discussão inicial desta introdução, como são tratadas as relações de poder contidas nestes Territórios.

É no primeiro ano de implementação do PTC que o Território adotado neste estudo é incorporado ao Programa, passando à condição de Território da Cidadania do Pontal do Paranapanema. Em se tratando de uma região marcada historicamente pela grilagem de terras devolutas e pela luta pela terra, buscamos, ao longo da pesquisa, compreender qual a orientação das ações oficiais do PTC, se estas realmente rompem com uma lógica setorial, qual o âmbito das intervenções estatais e como se dá a organização interna e a participação social no espaço do Colegiado Territorial frente os diferentes interesses em disputa neste espaço geográfico.

Encerrando esta introdução, esclarecemos que, neste momento, buscaremos apresentar reflexões acerca do que nos foi possível apreender durante o desenvolvimento da pesquisa, sobretudo, no que toca à participação social, operacionalização e orientação das ações estatais no Território estudado, sendo que discussão de maior amplitude teórica e conceitual a respeito das chamadas Políticas Territoriais pode ser encontrada em trabalhos anteriores ${ }^{4}$.

\footnotetext{
3 O decreto que institui o Programa apresenta os critérios utilizados na escolha dos Territórios a serem incorporados: estar incorporado ao Programa Desenvolvimento Sustentável de Territórios Rurais, do Ministério do Desenvolvimento Agrário; menor Índice de Desenvolvimento Humano IDH territorial; maior concentração de beneficiários do Programa Bolsa Família; maior concentração de agricultores familiares e assentados da reforma agrária; maior concentração de populações tradicionais, quilombolas e indígenas; baixo dinamismo econômico, segundo a tipologia das desigualdades regionais constantes da Política Nacional de Desenvolvimento Regional, do Ministério da Integração Nacional; convergência de programas de apoio ao desenvolvimento de distintos níveis de governo; maior organização social; maior concentração de municípios de menor IDEB - Índice de Desenvolvimento de Educação Básica (BRASIL, 2008).

${ }^{4}$ Consultar Rosa (2017) e Rosa e Ferreira (2017).
} 


\section{O PONTAL DO PARANAPANEMA: BREVE OLHAR SOBRE ALGUNS NÚMEROS}

Antes de iniciarmos a discussão a respeito das ações do PTC no Pontal do Paranapanema, é necessário que façamos - mesmo que de modo sucinto - a apresentação do recorte espacial utilizado pelo Governo Federal para a institucionalização deste Território da Cidadania 5 .

O Território da Cidadania do Pontal do Pontal do Paranapanema abrange uma área de aproximadamente 18. $441 \mathrm{~km}^{2}$, sendo composto por 32 municípios: Alfredo Marcondes, Álvares Machado, Anhumas, Caiabu, Caiuá, Emilianópolis, Estrela do Norte, Euclides da Cunha Paulista, Iepê, Indiana, João Ramalho, Marabá Paulista, Martinópolis, Mirante do Paranapanema, Nantes, Narandiba, Piquerobi, Pirapozinho, Presidente Bernardes, Presidente Epitácio, Presidente Prudente, Presidente Venceslau, Rancharia, Regente Feijó, Ribeirão dos Índios, Rosana, Sandovalina, Santo Anastácio, Santo Expedito, Taciba, Tarabai e Teodoro Sampaio (BRASIL, 2015).

A figura 1 nos fornece a localização do Território e identifica os municípios.

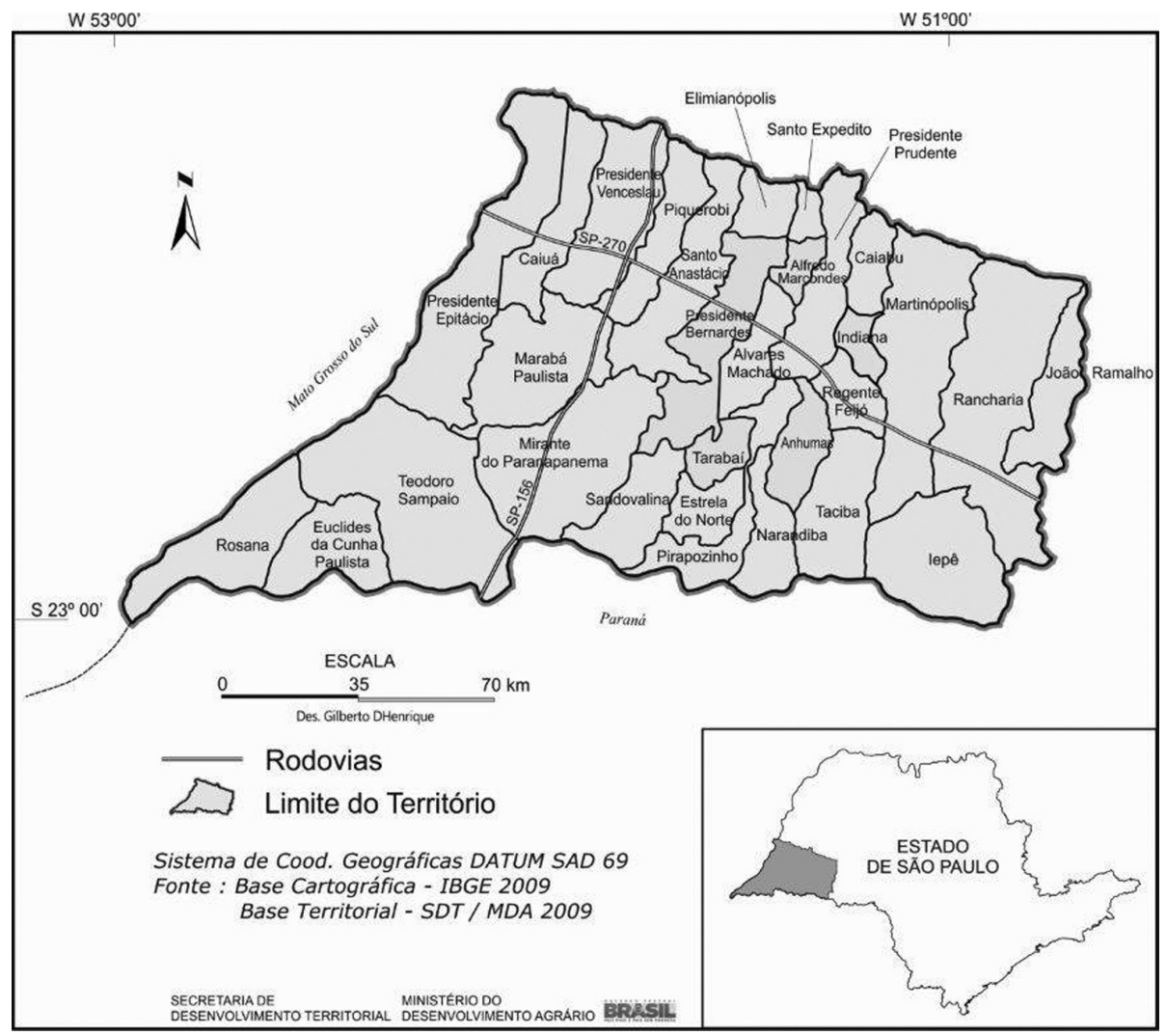

Figura 1 - Território da Cidadania do Pontal do Paranapanema

Fonte: MDA, 2016.

\footnotetext{
5 Mais uma vez, destacamos que informações mais completas e detalhadas sobre os municípios que compõem este Território podem ser encontradas em ROSA (2017).
} 
De acordo com números oficiais do Censo Demográfico de 2010, a população total do Território é de 583.703 habitantes, dos quais, 59.874 vivem na área rural, o que corresponde a $10,25 \%$ da população total. Possui 12.349 agricultores familiares e 5.853 famílias assentadas. Seu IDH médio é de 0,80 (BRASIL, 2015).

A tabela 1 nos mostra a evolução da distribuição da população entre área urbana e área rural de cada um dos 32 municípios que compõem o Território para a série histórica 1991 - 2000 - 2010.

\section{Tabela 1 - Distribuição da população dos municípios do Pontal do Paranapanema nos anos 1991, 2000 e 2010}

\begin{tabular}{|c|c|c|c|c|c|c|c|c|c|}
\hline Municípios & $\begin{array}{l}\text { Pop. } \\
\text { total } \\
(1991)\end{array}$ & $\begin{array}{l}\text { Pop. } \\
\text { total } \\
(2000)\end{array}$ & $\begin{array}{l}\text { Pop. } \\
\text { total } \\
(2010)\end{array}$ & $\begin{array}{l}\text { Pop. } \\
\text { rural } \\
(1991)\end{array}$ & \begin{tabular}{|l|} 
Pop. \\
rural \\
$(2000)$
\end{tabular} & $\begin{array}{l}\text { Pop. } \\
\text { rural } \\
(2010)\end{array}$ & $\begin{array}{l}\text { Pop. } \\
\text { urbana } \\
(1991)\end{array}$ & $\begin{array}{l}\text { Pop. } \\
\text { urbana } \\
(2000)\end{array}$ & $\begin{array}{l}\text { Pop. } \\
\text { urbana } \\
(2010)\end{array}$ \\
\hline $\begin{array}{l}\text { Alfredo } \\
\text { Marcondes }\end{array}$ & 3.493 & 3.697 & 3.891 & 1.203 & 1.025 & 636 & 2.290 & 2.672 & 3.255 \\
\hline $\begin{array}{l}\text { Álvares } \\
\text { Machado }\end{array}$ & 18.865 & 22.661 & 23.513 & 3.478 & 2.565 & 2.330 & 15.387 & 20.096 & 21.183 \\
\hline Anhumas & 3.242 & 3.411 & 3.738 & 1.360 & 904 & 679 & 1.882 & 2.507 & 3.059 \\
\hline Caiabu & 3.854 & 4.077 & 4.072 & 1.458 & 962 & 757 & 2.396 & 3.115 & 3.315 \\
\hline Caiuá & 3.341 & 4.192 & 5.039 & 1.881 & 2.423 & 3.109 & 1.460 & 1.769 & 1.930 \\
\hline Emilianópolis & 2.901 & 2.893 & 3.020 & 939 & 702 & 523 & 1.962 & 2.191 & 2.497 \\
\hline $\begin{array}{ll}\text { Estrela do } \\
\text { Norte }\end{array}$ & 2.777 & 2.625 & 2.658 & 1.124 & 839 & 559 & 1.653 & 1.786 & 2.099 \\
\hline $\begin{array}{l}\text { Euclides da } \\
\text { Cunha Paulista }\end{array}$ & 9.564 & 10.214 & 9.585 & 3.224 & 3.783 & 3.474 & 6.340 & 6.431 & 6.111 \\
\hline Iepê & 7.334 & 7.257 & 7.628 & 1.663 & 1.299 & 855 & 5.671 & 5.958 & 6.773 \\
\hline Indiana & 4.622 & 4.932 & 4.825 & 1.158 & 871 & 698 & 3.464 & 4.061 & 4.127 \\
\hline João Ramalho & 3.056 & 3.842 & 4.150 & 1.067 & 767 & 607 & 1.989 & 3.075 & 3.543 \\
\hline $\begin{array}{l}\text { Marabá } \\
\text { Paulista }\end{array}$ & 3.494 & 3.699 & 4.812 & 1.590 & 1.651 & 2.670 & 1.904 & 2.048 & 2.142 \\
\hline Martinópolis & 19.673 & 22.346 & 24.219 & 4.487 & 4.371 & 3.878 & 15.186 & 17.975 & 20.341 \\
\hline $\begin{array}{lr}\text { Mirante do } \\
\text { Paranapanema }\end{array}$ & 15.179 & 16.213 & 17.059 & 4.634 & 6.380 & 7.014 & 10.545 & 9.833 & 10.045 \\
\hline Nantes & 2.679 & 2.269 & 2.707 & 763 & 610 & 276 & 1.916 & 1.659 & 2.431 \\
\hline Naran & 3.138 & 3.743 & 4.288 & 1.212 & 1.461 & 1.183 & 1.926 & 2.282 & 3.105 \\
\hline Piquerobi & 3.268 & 3.478 & 3.537 & 964 & 1.024 & 868 & 2.304 & 2.454 & 2.669 \\
\hline Pirapozinho & 20.992 & 22.104 & 24.694 & 1.964 & 1.389 & 1.232 & 19.028 & 20.715 & 23.462 \\
\hline $\begin{array}{l}\text { Presidente } \\
\text { Bernardes }\end{array}$ & 13.410 & 14.662 & 13.570 & 4.487 & 4.508 & 3.070 & 8.923 & 10.154 & 10.500 \\
\hline $\begin{array}{l}\text { Presidente } \\
\text { Epitácio }\end{array}$ & 34.851 & 39.298 & 41.318 & 4.124 & 2.943 & 2.773 & 30.727 & 36.355 & 38.545 \\
\hline $\begin{array}{l}\text { Presidente } \\
\text { Prudente }\end{array}$ & 165.484 & 189.186 & 207.610 & 5.257 & 3.957 & 4.235 & 160.227 & 185.229 & 203.375 \\
\hline $\begin{array}{l}\text { Presidente } \\
\text { Venceslau }\end{array}$ & 36.120 & 37.347 & 37.910 & 1.732 & 2.793 & 1.638 & 34.388 & 34.554 & 36.272 \\
\hline Rancharia & 26.913 & 28.772 & 28.804 & 3.837 & 3.783 & 2.976 & 23.076 & 24.989 & 25.828 \\
\hline Regente Feijó & 14.963 & 16.998 & 18.494 & 2.670 & 1.732 & 1.445 & 12.293 & 15.266 & 17.049 \\
\hline
\end{tabular}


(continuação)

\begin{tabular}{l|c|c|c|c|c|c|c|c|c}
\hline $\begin{array}{l}\text { Ribeirão dos } \\
\text { Índios }\end{array}$ & 2.119 & 2.222 & 2.187 & 531 & 462 & 337 & 1.588 & 1.760 & 1.850 \\
\hline Rosana & 20.738 & 24.229 & 19.691 & 15.733 & 18.031 & 3.833 & 5.005 & 6.198 & 15.858 \\
\hline Sandovalina & 2.403 & 3.089 & 3.699 & 758 & 1.339 & 1.118 & 1.645 & 1.750 & 2.581 \\
\hline $\begin{array}{l}\text { Santo } \\
\text { Anastácio }\end{array}$ & 19.960 & 20.749 & 20.475 & 2.497 & 1.705 & 1.395 & 17.463 & 19.044 & 19.080 \\
\hline $\begin{array}{l}\text { Santo } \\
\text { Expedito }\end{array}$ & 2.222 & 2.526 & 2.803 & 593 & 525 & 325 & 1.629 & 2.001 & 2.478 \\
\hline Taciba & 4.750 & 5.221 & 5.714 & 1.439 & 979 & 862 & 3.311 & 4.242 & 4.852 \\
\hline Tarabai & 4.714 & 5.786 & 6.607 & 783 & 559 & 498 & 3.931 & 5.227 & 6.109 \\
\hline $\begin{array}{l}\text { Teodoro } \\
\text { Sampaio }\end{array}$ & 18.934 & 20.003 & 21.386 & 3.358 & 4.081 & 4.021 & 15.576 & 15.922 & 17.365 \\
\hline
\end{tabular}

Fonte: Instituto Brasileiro de Geografia e Estatística, 2010 e Atlas Brasil do Desenvolvimento Humano, 2017. (Organizado pelo autor).

Observando a tabela 1 notamos que, com base no Censo Demográfico (2010), dos 32 municípios que compõem o Território, o município de Presidente Prudente, com população aproximada de 200 mil habitantes, ocupa lugar de destaque, atuando como polo regional, sendo, também, o único em que a população ultrapassa os 50 mil habitantes, limite máximo de população média entre os municípios utilizado como critério para a implantação dos Territórios da Cidadania. Sendo que os demais municípios, em sua maioria, são de pequeno número de habitantes, com fortes traços rurais e dinâmicas internas diretamente relacionadas às atividades agropecuárias. Com estas características, chamam atenção municípios em que a população rural ultrapassa a população urbana, são os casos de Caiuá (2010), com 3.109 habitantes na área rural e 1.930 habitantes na área urbana, e Marabá Paulista (2010), com suas áreas rural e urbana apresentando, respectivamente, 2.670 habitantes e 2.142 habitantes.

Cabe destacar que, embora, de maneira geral, tenha havido uma diminuição de $26,95 \%$ da população rural no período apresentado (1991 a 2010), o que corresponde a, aproximadamente, 22.094 habitantes, alguns municípios apresentaram crescimento desta população ao longo dos anos, seja para toda a série histórica, seja apenas em dado momento do período. São os casos dos municípios contidos no Quadro 1.

\section{Quadro 1 - Municípios com Aumento de População Rural no Período 1991 - 2000 - 2010}

\begin{tabular}{l|l|}
\hline Municípios & Aumento de População Rural \\
\hline Caiuá & 1.228 pessoas em todo o período \\
\hline Euclides da Cunha Paulista & 250 pessoas em todo o período \\
\hline Marabá Paulista & 1.080 pessoas em todo o período \\
\hline Mirante do Paranapanema & 2.380 pessoas em todo o período \\
\hline Narandiba & 249 pessoas entre 1991 e 2000 \\
\hline Piquerobi & 60 pessoas entre 1991 e 2000 \\
\hline Presidente Bernardes & 21 pessoas entre 1991 e 2000 \\
\hline Presidente Venceslau & 1.061 pessoas entre 1991 e 2000 \\
\hline Rosana & 2.298 pessoas entre 1991 e 2000 \\
\hline Sandovalina & 360 pessoas em todo o período \\
\hline Teodoro Sampaio & 663 pessoas em todo o período \\
\hline
\end{tabular}

Fonte: Fonte: Instituto Brasileiro de Geografia e Estatística, 2010 e Atlas Brasil do Desenvolvimento Humano, 2017. (Organizado pelo autor). 
Mesmo que, a princípio, alguns números não pareçam muito expressivos, é importante que sejam analisados, pois tal movimento se deve, em grande medida, às mobilizações e ocupações de terras por trabalhadores rurais sem-terra, e pela consequente implantação de assentamentos rurais em vários destes municípios, sobretudo, na década de 1990.

O processo de implantação dos assentamentos rurais, mesmo desempenhando importante função na transformação da estrutura fundiária da região, ainda tem muito que avançar, já que as populações camponesas e os assentamentos rurais no Pontal do Paranapanema ainda convivem lado a lado com o latifúndio, conforme Plano Territorial de Desenvolvimento Rural Sustentável - PTDRS (2011).

\begin{abstract}
A expansão da população em áreas de assentamento revela uma situação sempre presente no território: a relação entre a existência de grandes propriedades apesar da expansão das pequenas unidades agrícolas, pois os domínios de extensões baseadas no agronegócio (grande propriedade) ainda não se modernizaram e partes das terras não cultivadas formam reserva de valor (p. 20).
\end{abstract}

A tabela 2 nos mostra o número de assentamentos rurais e famílias assentadas nos municípios do Território.

\title{
Tabela 2 - Assentamentos rurais e famílias assentadas no Pontal do Paranapanema
}

\begin{tabular}{l|c|c}
\hline \multicolumn{1}{c|}{ Municípios } & $\begin{array}{c}\text { No de } \\
\text { Assentamentos }\end{array}$ & $\begin{array}{c}\text { Famílias } \\
\text { assentadas }\end{array}$ \\
\hline Alfredo Marcondes & 0 & 0 \\
\hline Álvares Machado & 0 & 0 \\
\hline Anhumas & 0 & 0 \\
\hline Caiabu & 0 & 0 \\
\hline Caiuá & 6 & 366 \\
\hline Emilianópolis & 0 & 0 \\
\hline Estrela do Norte & 0 & 0 \\
\hline Euclides da Cunha & 10 & 653 \\
\hline Iepê & 1 & 29 \\
\hline Indiana & 0 & 0 \\
\hline João Ramalho & 1 & 37 \\
\hline Marabá Paulista & 6 & 269 \\
\hline Martinópolis & 2 & 124 \\
\hline Mirante do Paranapanema & 34 & 1.561 \\
\hline Nantes & 0 & 0 \\
\hline
\end{tabular}


(continuação)

\begin{tabular}{l|c|c}
\hline Narandiba & 0 & 0 \\
\hline Piquerobi & 3 & 84 \\
\hline Pirapozinho & 0 & 0 \\
\hline Presidente Bernardes & 8 & 266 \\
\hline Presidente Epitácio & 0 & 345 \\
\hline Presidente Prudente & 7 & 0 \\
\hline Presidente Venceslau & 2 & 340 \\
\hline Rancharia & 0 & 178 \\
\hline Regente Feijó & 1 & 0 \\
\hline Ribeirão dos Índios & 4 & 40 \\
\hline Rosana & 2 & 628 \\
\hline Sandovalina & 0 & 198 \\
\hline Santo Anastácio & 0 & 0 \\
\hline Santo Expedito & 0 & 0 \\
\hline Taciba & 0 & 0 \\
\hline Tarabaí & 21 & 0 \\
\hline Teodoro Sampaio & 075 \\
\hline Fonte: Fundaço & 8940 \\
\hline
\end{tabular}

Fonte: Fundação Instituto de Terras do Estado de São Paulo

"José Gomes da Silva" - ITESP, 2013. (Organizado pelo autor).

A tabela 2 nos revela um total de 112 assentamentos rurais na região, sendo 5.993 famílias assentadas, números que expressam a importância da construção de políticas públicas que possibilitem a permanência e reprodução social das famílias camponesas já assentadas e a democratização do acesso à terra, com a formação de novos assentamentos, contribuindo, assim, na dinamização das economias dos municípios, construção de novas formas de sociabilidade, transformação da estrutura fundiária regional, geração de empregos e, consequente, redução da concentração de renda.

Dialogando com a presença dos assentamentos rurais - mas não apenas -, a tabela 3 nos mostra a importância das atividades agropecuárias para as economias dos municípios do Território, dado o alto percentual de ocupados neste setor.

Um olhar atento sobre a tabela 3 nos revela que, à exceção de Presidente Prudente - polo regional onde, predominantemente, se concentram as atividades ligadas aos setores da indústria e de serviços - todos os demais municípios apresentam percentual de ocupados no setor agropecuário bem maior que o percentual estadual. Podemos observar, também, que, em comparação ao percentual nacional, 23 municípios apresentam maior número de ocupados em atividades ligadas a este setor. 
Tabela 3 - Percentual dos ocupados por setor da economia nos municípios do Pontal do Paranapanema

\begin{tabular}{|c|c|c|c|c|c|c|c|}
\hline Municípios & $\begin{array}{c}\text { \% dos } \\
\text { ocupado } \\
\text { s no } \\
\text { setor } \\
\text { agropec } \\
\text { uário- } \\
18 \text { anos } \\
\text { ou mais } \\
(2010)\end{array}$ & $\begin{array}{c}\text { \% dos } \\
\text { ocupado } \\
\text { s no } \\
\text { setor } \\
\text { extrativo } \\
\text { mineral - } \\
18 \text { anos } \\
\text { ou mais } \\
(2010)\end{array}$ & $\begin{array}{c}\text { \% dos } \\
\text { ocupados } \\
\text { na } \\
\text { indústria } \\
\text { de } \\
\text { transform } \\
\text { ação - 18 } \\
\text { anos ou } \\
\text { mais } \\
(2010)\end{array}$ & $\begin{array}{c}\text { \% dos } \\
\text { ocupado } \\
\text { s no } \\
\text { SIUP - } \\
18 \text { anos } \\
\text { ou mais } \\
\text { (2010) }\end{array}$ & $\begin{array}{c}\text { \% dos } \\
\text { ocupados } \\
\text { no setor } \\
\text { de } \\
\text { construção } \\
-18 \text { anos } \\
\text { ou mais } \\
\text { (2010) }\end{array}$ & $\begin{array}{c}\text { \% dos } \\
\text { ocupado } \\
\text { s no } \\
\text { setor } \\
\text { comércio } \\
\text { - } 18 \text { anos } \\
\text { ou mais } \\
(2010)\end{array}$ & $\begin{array}{c}\text { \% dos } \\
\text { ocupado } \\
\text { s no } \\
\text { setor } \\
\text { serviços } \\
\text { - } 18 \text { anos } \\
\text { ou mais } \\
\text { (2010) }\end{array}$ \\
\hline Brasil & 13,55 & 0,48 & 11,92 & 0,93 & 7,40 & 15,38 & 44,29 \\
\hline São Paulo & 4,26 & 0,18 & 16,14 & 0,88 & 6,86 & 15,27 & 48,36 \\
\hline $\begin{array}{l}\text { Alfredo } \\
\text { Marcondes }\end{array}$ & 16,39 & -- & 8,28 & 0,69 & 8,34 & 11,99 & 47,07 \\
\hline $\begin{array}{l}\text { Álvares } \\
\text { Machado }\end{array}$ & 9,92 & 0,17 & 13,14 & 1,33 & 11,56 & 19,99 & 41,71 \\
\hline Anhumas & 24,05 & -- & 8,80 & -- & 8,49 & 13,70 & 35,42 \\
\hline Caiabu & 30,94 & -- & 33,8 & 0,20 & 2,94 & 6,35 & 25,06 \\
\hline Caiuá & 35,95 & -- & 9,22 & 1,24 & 4,47 & 4,46 & 40,80 \\
\hline Emilianópolis & 33,72 & -- & 9,91 & 0,16 & 5,95 & 7,25 & 41,07 \\
\hline $\begin{array}{ll}\begin{array}{l}\text { Estrela do } \\
\text { Norte }\end{array} & \text { do } \\
\end{array}$ & 16,41 & 0,33 & 22,43 & 0,17 & 14,63 & 6,53 & 37,38 \\
\hline $\begin{array}{ll}\text { Euclides da } \\
\text { Cunha } \\
\text { Paulista }\end{array}$ & 37,20 & -- & 17,68 & 0,64 & 6,35 & 7,87 & 28,82 \\
\hline Iepê & 23,97 & 0,09 & 11,03 & 0,91 & 6,39 & 11,39 & 42,31 \\
\hline Indiana & 12,96 & 0,07 & 22,23 & 0,64 & 7,65 & 14,81 & 39,00 \\
\hline João Ramalho & 27,31 & -- & 29,71 & 3,52 & 4,62 & 8,20 & 24,97 \\
\hline $\begin{array}{l}\text { Marabá } \\
\text { Paulista }\end{array}$ & 34,16 & -- & 15,94 & 0,60 & 2,85 & 2,83 & 42,25 \\
\hline Martinópolis & 13,38 & -- & 22,27 & 0,35 & 6,83 & 10,61 & 42,64 \\
\hline $\begin{array}{l}\text { Mirante do } \\
\text { Paranapane- } \\
\text { ma }\end{array}$ & 33,84 & -- & 15,19 & 1,06 & 4,46 & 9,37 & 31,47 \\
\hline Nantes & 20,95 & -- & 17,53 & -- & 3,68 & 8,49 & 46,09 \\
\hline Narandiba & 14,27 & 2,91 & 33,71 & 0,75 & 4,82 & 7,33 & 30,65 \\
\hline Piquerobi & 29,78 & -- & 12,29 & 0,44 & 6,06 & 5,77 & 42,32 \\
\hline Pirapozinho & 6,90 & 0,19 & 19,13 & 1,85 & 9,19 & 19,02 & 38,16 \\
\hline $\begin{array}{l}\text { Presidente } \\
\text { Bernardes }\end{array}$ & 19,74 & 0,16 & 7,00 & 1,13 & 7,90 & 13,46 & 45,79 \\
\hline $\begin{array}{l}\text { Presidente } \\
\text { Epitácio }\end{array}$ & 9,51 & 0,52 & 15,74 & 1,35 & 9,01 & 17,49 & 41,81 \\
\hline $\begin{array}{l}\text { Presidente } \\
\text { Prudente }\end{array}$ & 2,89 & 0,13 & 11,17 & 1,40 & 7,11 & 19,92 & 54,04 \\
\hline $\begin{array}{l}\text { Presidente } \\
\text { Venceslau }\end{array}$ & 8,55 & 0,06 & 12,63 & 1,08 & 6,65 & 14,80 & 52,94 \\
\hline Rancharia & 15,03 & -- & 15,91 & 0,74 & 6,10 & 16,47 & 42,40 \\
\hline Regente Feijó & 11,35 & -- & 15,27 & 0,59 & 7,39 & 18,60 & 45,17 \\
\hline
\end{tabular}


(continuação)

\begin{tabular}{l|c|c|c|c|c|c|c}
\hline $\begin{array}{l}\text { Ribeirão dos } \\
\text { Índios }\end{array}$ & 37,03 & -- & 11,21 & 0,75 & 5,18 & 9,02 & 34,72 \\
\hline Rosana & 14,61 & 0,77 & 5,49 & 5,65 & 12,27 & 14,06 & 44,48 \\
\hline Sandovalina & 30,12 & -- & 13,94 & 0,46 & 7,64 & 9,46 & 38,02 \\
\hline $\begin{array}{l}\text { Santo } \\
\text { Anastácio }\end{array}$ & 13,15 & 0,33 & 13,53 & 1,49 & 7,93 & 15,68 & 46,13 \\
\hline $\begin{array}{l}\text { Santo } \\
\text { Expedito }\end{array}$ & 13,87 & -- & 20,48 & 1,22 & 7,78 & 10,24 & 44,76 \\
\hline Taciba & 34,57 & 0,61 & 10,08 & 0,47 & 5,70 & 10,92 & 35,02 \\
\hline Tarabai & 14,56 & -- & 24,55 & 0,60 & 9,23 & 13,70 & 36,73 \\
\hline $\begin{array}{l}\text { Teodoro } \\
\text { Sampaio }\end{array}$ & 18,10 & 0,08 & 21,95 & 0,99 & 7,05 & 12,11 & 35,88 \\
\hline
\end{tabular}

Fonte: Instituto Brasileiro de Geografia e Estatística, 2010 e Atlas Brasil do Desenvolvimento Humano, 2017. (Organizado pelo autor).

Na comparação entre os setores, nota-se que, com relação ao comércio, o setor agropecuário apresenta maior percentual de ocupados em 23 municípios. Em comparação à indústria, a agropecuária apresenta maior percentual de ocupados em 15 municípios, ou seja, pouco menos da metade destes, o que ainda demonstra sua importância na geração de empregos no Território. E, por último, na comparação com o setor de serviços, este apresenta maior percentual de ocupados na grande maioria dos municípios analisados, 27 destes.

Dentre as atividades agropecuárias mencionadas, a pecuária tem forte relação com o processo de ocupação das terras do Pontal do Paranapanema, se fazendo presente, ainda hoje, seja em grandes propriedades onde a atividade é voltada à criação de gado de corte - sendo comum a observação de amplas áreas de pastagens degradas pela erosão - , seja em assentamentos rurais, onde, predominantemente, se desenvolve a pecuária leiteira, sendo também comum a existência de pastagens degradadas e sem o correto manejo.

A ocupação rural intensiva baseada na agropecuária, desmatamento, na agricultura e a pastagem extensiva ainda se desenvolvem numa região de solos arenosos que transformaram profundamente a paisagem, provocando erosão, lixiviação do solo e assoreamento dos cursos d'água (MDA, 2011, p. 13).

A pecuária leiteira é desenvolvida, predominantemente, nos assentamentos rurais, representando importante fonte de renda para as famílias assentadas, entretanto, de maneira geral, sua produtividade ainda é baixa, carecendo de melhoramento genético de rebanhos, manejo de pastagens e verticalização da produção que proporcione maior autonomia às famílias. Sendo de grande importância que os produtores passem a controlar mais etapas da cadeia produtiva, possibilitando, assim, ficarem menos sujeitos aos preços estabelecidos pelos laticínios e às flutuações de mercado. Mais à frente veremos como a cadeia produtiva do leite - junto à olericultura, também muito praticada no Território - foi alvo de diversas ações no âmbito do PTC.

A cadeia do leite na região é pouco verticalizada, e este fato ficou evidente nas oficinas de atualização do PTDRS. Diversas propostas indicaram que é necessária à execução de projetos integrados para industrializar a produção de pequenos produtores familiares, possibilitando a diversifica- 
ção de produtos, e a obtenção de melhores preços [...] (MDA, 2011, p. 38).

Por meio desta sucinta apresentação da área de estudo, buscamos mostrar a importância das atividades agropecuárias e como estas exercem forte influência sobre a organização e dinâmicas internas destes municípios de intensa relação campocidade. Chamamos atenção, ainda, para concentração de renda existente nos municípios desta área. Concentração esta que, em grande parte, deriva da presença ainda marcante de latifúndios destinados, sobretudo, à prática da pecuária extensiva e sobre os quais se dá também a expansão do agronegócio canavieiro.

\section{A INSTITUCIONALIZAÇÃO DO TERRITÓRIO DA CIDADANIA DO PONTAL DO PARANAPANEMA}

Após breve discussão a respeito do caminho percorrido pelas chamadas Políticas Territoriais desde sua emergência no exterior, sua abordagem escalar e transposição à América Latina no início dos anos 2000 e, também, apresentação de alguns dados do Território importantes a este trabalho, passamos, então, à discussão a respeito da forma como governo federal e representantes da sociedade civil e do poder público têm buscado construir o desenvolvimento territorial rural no Pontal do Paranapanema.

Para isso, iniciaremos a discussão remetendo ao ano de 2004, quando, conforme nos relata E.B.V., ex-assessora territorial, foram iniciados os primeiros diálogos entre membros da sociedade civil e entidades do Território e a SDT. De acordo com a entrevistada, o contato inicial partiu da SDT, por meio de sua articuladora estadual. O relato da entrevistada coaduna-se com o que dizem Delgado e Grisa (2013) sobre os diálogos iniciais entre SDT e sociedade civil e a recepção com que esta recebe as políticas territoriais.

[...] de modo geral, a política territorial "chegou" até os espaços locais por iniciativa da SDT, sendo rapidamente apropriada e conduzida pelos atores locais. Ainda que as trajetórias de participação e de protagonismo social sejam muito diversas entre os territórios, devido às características históricas, políticas, econômicas, sociais e culturais de cada um, em todos os casos foi possível observar certa expectativa e entusiasmo dos atores locais, sobretudo da sociedade civil, com a construção de políticas descentralizadas, bottom-up e com uma escala de governança mais ampla do que o município. Essas características ofereciam oportunidades de construção de políticas mais coladas às necessidades e demandas dos atores locais e em uma escala mais propícia à viabilização de ações coordenadas entre eles, tendo em vista a geração de processos endógenos e sustentáveis de desenvolvimento local. Ademais, a perspectiva territorial criava uma expectativa de que a valorização de um conjunto mais amplo e complexo de interações sociais poderia estimular a construção de uma governança local mais democrática e mais apta a minimizar a reprodução do poder político tradicional, ancorado no município e baseado em relações essencialmente clientelistas (DELGADO; GRISA, 2013, p. 242). 
Estabelecido o contato entre SDT e Território, no ano de 2005 é instituída a Comissão de Instalação de Ações Territoriais (CIAT), de caráter transitório e com objetivo de estabelecer comunicação com a sociedade a respeito do processo que se iniciava, articulando os diferentes sujeitos, grupos sociais, instituições e organizações do Território, procurando, assim, animar o desenvolvimento territorial por meio do estímulo à participação social nos espaços de discussão e representação. De acordo com o PTDRS do Território (2011), neste primeiro momento, para mobilizar os chamados agentes territoriais, a CIAT contava com representantes do poder público e da sociedade civil, em sua maioria ligados às questões rurais e agrárias do recém institucionalizado Território Rural do Pontal do Paranapanema.

Nesse período foi constituída a Comissão de Instalação das Ações Territoriais - CIAT, formada por representantes de movimentos sociais de luta pela terra - MST, MAST, Uniterra; federações de agricultores/trabalhadores rurais - Fetaesp e Feraesp; representantes de associações de produtores assentados de reforma agrária, sindicato de trabalhadores rurais, Institutos de Pesquisas - IPÊ e APOENA e Comissão Pastoral da Terra - CPT.

Do poder público estavam presentes na constituição da CIAT o Instituto Nacional de Colonização e Reforma Agrária INCRA, Coordenadoria de Assistência Técnica Integrada CATI, Instituto de Terras do Estado de São Paulo - ITESP, Universidade Estadual de São Paulo - UNESP e Prefeituras de nove municípios sendo Teodoro Sampaio, Presidente Epitácio, Presidente Venceslau, Marabá Paulista, Mirante do Paranapanema, Caiuá, Santo Anastácio, Euclides da Cunha e Estrela do Norte (MDA, 2011, p. 63).

De acordo com documentação analisada, a CIAT era constituída por dezenove entidades da sociedade civil, num total de trinta e sete representantes, e treze entidades ligadas ao poder público, contabilizando vinte e dois representantes. O documento ainda revela que das dezenove entidades representativas da sociedade civil, dezessete estavam ligadas diretamente às questões rurais, agrícolas e/ou agrárias, sendo associações e cooperativas de produtores rurais, sindicatos de trabalhadores rurais e movimentos sociais de luta pela terra. Com relação à representação do poder público, das treze entidades componentes, três eram instituições de ATER (ITESP, INCRA e CATI) e nove eram prefeituras de pequenos municípios de base econômica marcadamente agropecuária. Esta composição revela a orientação ainda fortemente setorial da política territorial à época.

Conforme contido no PTDRS (2011), após três anos de atividades e amadurecimento, a CIAT deixa de ter caráter provisório, tornando-se um colegiado permanente, o Colegiado de Desenvolvimento Territorial do Pontal do Paranapanema (CODETER Pontal). É, também, no ano de 2008 que o Território Rural é incorporado ao Programa Territórios da Cidadania, passando a constituir-se como Território da Cidadania do Pontal do Paranapanema.

Nos afirma a entrevistada E.B.V. que a incorporação do Território ao PTC representou grande mudança na forma de organização dos trabalhos e, também, no interesse tanto de representantes da sociedade civil, quanto do poder público. Mudava, também, a própria orientação da política pública, que passava a operar numa complexa articulação interministerial que prometia romper definitivamente com a compartimentação setorial das ações nos Territórios. Com a homologação do Território da Cidadania do Pontal do Paranapanema, ocorre uma expansão, inclusive do, a partir de então, denominado Colegiado Territorial, que passa a contar com novos sujeitos sociais e instituições que até então não ocupavam este espaço. 
A respeito do maior interesse, por parte dos agentes públicos, no novo Programa que surgia, Delgado e Grisa (2013) nos dizem que

[...] Este na verdade foi um dos objetivos do PTC, tentando reverter a hostilidade ou desconfiança inicial dos prefeitos em relação à política territorial. Tratando-se de um programa federal com maior expressão política - por estar vinculado diretamente à Casa Civil da Presidência, e anunciando expressiva quantidade de recursos provenientes de um grande número de ministérios a serem investidos nos territórios - o PTC demonstrou-se atrativo para os gestores municipais que criaram expectativas de, por meio dele, acessarem mais recursos financeiros, ações e políticas públicas para seus municípios, seja via institucionalidades territoriais, seja diretamente por meio de suas relações políticas (p. 256).

O Colegiado de Desenvolvimento Territorial constitui-se em um espaço coletivo de discussão e tomadas de decisões, com caráter definitivo e deliberativo, e com o objetivo principal de promover a construção de propostas coletivas e traçar estratégias que possibilitem, por meio da organização e participação social, o desenvolvimento do Território.

Com a incorporação do Território ao PTC e a formação do CODETER, aumenta a participação de sujeitos sociais que até então não compunham a gestão social da política territorial. Este aumento no número de integrantes, de acordo com o PTDRS (2011), leva a mudanças na estrutura organizacional do Colegiado.

\begin{abstract}
A partir de 2008, o território Pontal do Paranapanema passou a fazer parte do Programa Territórios da Cidadania, provocando mudança na composição e na estrutura interna, em razão da ampliação da diversidade de temáticas e políticas públicas discutidas no âmbito do CODETER. Houve então, a ampliação da participação de atores que não estavam integrados [...] (MDA, 2011, p. 64).
\end{abstract}

Feita a apresentação sobre a forma como se deu a institucionalização do Território alvo deste estudo, passaremos à discussão acerca das ações desenvolvidas pelo Programa Territórios da Cidadania, sob coordenação do CODETER, no Pontal do Paranapanema.

\title{
O PROGRAMA TERRITÓRIOS DA CIDADANIA: AÇÕES E PARTICIPAÇÃO SOCIAL
}

No decorrer da pesquisa pudemos notar grande rotatividade na participação dos chamados atores territoriais. À exceção do "núcleo duro" do Colegiado, composto por membros do Núcleo Diretivo e mais alguns integrantes de Câmaras Temáticas, a participação da maior parte dos representantes e demais atores que, de alguma forma, se relacionam às atividades do Colegiado, se mostrou intermitente, não parecendo haver forte compromisso com a gestão social da política territorial.

A pesquisa de campo revelou participação mais assídua dos representantes da sociedade civil, quando em comparação aos representantes do poder público. Esta diferença no envolvimento pode se dar devido ao maior entusiasmo da sociedade civil com as possibilidades de discutir e propor seus projetos e demandas em uma esfera 
não mais controlada pelos poderes públicos municipais. Quanto à menor participação do poder público, tal situação pode ser explicada - entre outros fatores - por rivalidades político-partidárias entre instituições de diferentes níveis de governo e ligadas à diferentes partidos políticos que, a priori, se colocam em oposição a políticas formuladas por instituições e grupos tidos como rivais. Tal postura pode impor limitações à integração de ações e políticas de diferentes esferas, um dos objetivos apregoados pelas políticas de desenvolvimento territorial.

Em se tratando, ainda, da baixa assiduidade de representantes do poder público, esta participação parece estar bastante vinculada à maior ou menor disponibilidade de recursos financeiros. Assim, quando está em pauta a liberação de recursos, o interesse deste segmento aumenta significativamente. É evidente que este maior interesse e participação quando há editais abertos e possíveis liberações de recursos é notado, também, entre os representantes da sociedade civil, entretanto, tal postura é mais pronunciada por parte do poder público.

Vejo diferença grande, assim, a participação é muito maior da sociedade civil, embora tenha todas as dificuldades para participar, participação sempre foi maior da sociedade civil. O poder público, a gente percebe que tem poucas pessoas que tenham uma afinidade com a temática do desenvolvimento territorial, que se envolvem mais, mas a maioria dos representantes do poder público não se envolve, participam nos momentos em que tem edital aberto, então vem para o colegiado para buscar recursos, não para contribuir com o desenvolvimento da região e eu percebo muito essa visão setorial nos representantes do poder público, enquanto a sociedade civil já amadureceu num sentido de, por exemplo, discutir um projeto de PROINF e ter a consciência de que o melhor projeto vai ser aquele que traz um benefício maior para o Território e não para o município dela, o poder público não, o poder público vai para brigar para levar o recurso para o seu município, independente de aquele projeto ser o que vai contribuir melhor para o desenvolvimento, se está no contexto da discussão [...]. (E.B.V., Presidente Prudente, 22 de fevereiro de 2017).

A análise da Matriz de Ações Territoriais e projetos aprovados via editais do PROINF, compreendendo o período 2003 - 2015, revela certa concentração de projetos contemplados e valores de recursos nos municípios de Teodoro Sampaio, Mirante do Paranapanema e Presidente Venceslau, além de Presidente Prudente, onde os projetos, em grande parte, foram voltados para estruturação e apoio às atividades do Colegiado. Os demais citados são municípios com maior envolvimento nas atividades do CODETER, forte organização social, maior número de famílias assentadas e entidades representativas, movimento social atuante e poder público com participação mais ativa e maior interesse na política territorial.

Em que pese o PROINF se destinar ao apoio de atividades produtivas dos segmentos ligados à agricultura familiar nos Territórios, o rol de projetos elencados revela baixa diversidade de atividades agropecuárias abrangidas. Podendo-se destacar a quantidade de projetos vinculados à cadeia produtiva do leite, sobretudo no que toca à aquisição de tanques de expansão e resfriamento de leite.

O ex-Diretor de Agricultura e atual vereador do município de Euclides da Cunha Paulista conta a respeito deste momento e destas ações no município.

[...] nós temos ligação com o CODETER, com o Território da Cidadania, porque através deles a gente teve beneficiamento, 
já ganhamos tanques de resfriamento, e pra gente é importante estreitar o quanto mais a parceria com o Território [...] o Território em 2012, 2011, principalmente naquela época que veio aquele monte de resfriador, foi tudo por ele $[\ldots]$

[os resfriadores] vieram para o município e o município repassava, tinha uma norma do MDA, que a gente tinha que repassar para os assentados, mas tinha todo um procedimento legal, foi até o jurídico que criou, tinha que ter três colaboradores. A Caixa mandava o recurso até pra fazer o abrigo desses resfriadores [...] (D.F.F.A., Euclides da Cunha Paulista, 10 de fevereiro de 2017).

A respeito do controle por parte dos laticínios, da apropriação das políticas públicas e da necessidade de autonomia dos agricultores na cadeia produtiva do leite, o agricultor e liderança do Movimento dos Trabalhadores Rurais Sem Terra (MST), Z.L.S., nos traz importantes contribuições.

[...] infraestrutura para captação de leite foi colocada bastante, e na época a gente ajudou a pensar isso, a ideia era para dar às comunidades a autonomia para que elas pudessem comercializar seu leite autonomamente. O resultado é que essas comunidades, a maioria delas, não deu conta de sair do circuito dos laticínios locais e regionais aí instalados na perspectiva da comercialização. Então foram inúmeros laticínios comunitários que foram feitos o repasse via PRONAF Infraestruturas, muitos deles estão em funcionamento, mas nenhum com grande impacto de romper com a lógica dos atravessadores ou das agroindústrias de leite que estão aí instalados [...]. Quando vem essa política do Territórios da Cidadania para que os agricultores se empoderem, protagonizem uma perspectiva de comercialização, eles [laticínios] saem na frente e melhoram as relações econômicas com esses agricultores em um primeiro momento, e os agricultores continuaram ali no mesmo circuito de comercialização, não conseguiram romper com isso. Isso todos os laticínios daqui fizeram [...]. E pouquíssimas iniciativas de verticalização da produção, ninguém pensou em fazer um requeijão, fazer um queijo, fazer uma mussarela, trabalhar outras iniciativas, até porque, do ponto de vista da legislação, implicava em ter um SIM, ter um sistema de inspeção mais qualificado, o SUASA ainda não estava na ordem do dia, enfim, um conjunto de fatores limitantes fez com que o agricultor entre uma visão estratégica, pensada pelos técnicos, pelos dirigentes e movimentos sociais e pelos representantes de órgãos públicos que pensaram nessa perspectiva, o agricultor fez a opção de seguir, até mesmo por conta da insegurança, da pouca informação, da pouca capacitação, eles fizeram o caminho que... e é assim com o ser humano, né? Entre o novo e o velho, fico seguro se eu ficar com o velho, com as velhas práticas, os velhos costumes (Z.L.S., Teodoro Sampaio, 16 de dezembro de 2016).

Além dos tanques de expansão e resfriamento de leite, nota-se, a partir dos projetos contemplados, apoio a grande quantidade de ações relacionadas à estruturação de hortas comunitárias, viveiros de mudas, feiras livres e, também, apoio à aquisição de veículos destinados às atividades de ATER nos municípios e à comercialização de produção via programas institucionais de compra de alimentos. 
Sobre o apoio do PROINF a estas atividades, alguns entrevistados nos falam a respeito.

No começo era muito resfriador porque tinha uma normativa do Ministério da Agricultura que exigia que o leite fosse resfriado, então foi muito resfriador. E aí depois foram alguns viveiros, hortas comunitárias, muitos kits de irrigação, infraestruturas bem simples mesmo e pulverizadas para diversos assentamentos e municípios. Muitos veículos para assistência técnica dos municípios, caminhões também. E teve algumas coisas, assim, como algumas feiras [...] (E.B.V., Presidente Prudente, 22 de fevereiro de 2017).

Olha, a maioria desses caminhõezinhos que puxa, que transporta, que faz a logística do programa PAA, veio do Território da Cidadania. Do PROINF, do PRONAF Infraestruturas.

[...] Sempre via PROINF. A maioria deles. Onde tem um caminhãozinho ali, que a prefeitura vai lá pegar nas associações e trazer para o banco de alimentos. Banco de alimentos também, alguns bancos de alimentos tiveram aporte do PROINF [...] (Z.L.S., Teodoro Sampaio, 16 de dezembro de 2016).

A relação de projetos apoiados corrobora com o que a participação nas atividades do Colegiado e o contato com seus membros revelou, uma significativa dificuldade da política territorial em romper com a visão setorial ainda predominante, seja na compreensão dos representantes tanto da sociedade civil, quanto do poder público, seja na própria orientação das ações. Entretanto, embora sejam predominantes as pautas voltadas às atividades produtivas, outras discussões e atividades são desenvolvidas sob coordenação do Colegiado Territorial, cabendo destaque às Conferências Territoriais abrangendo temáticas como saúde, segurança alimentar, educação, juventude, entre outras.

Em que pese algumas atividades como as citadas serem desenvolvidas, parece haver grande dificuldade de articulação não apenas entre os diferentes atores territoriais, mas também na própria interação interministerial, uma das características mais exaltadas como inovação do Programa Territórios da Cidadania.

Relacionando-se com a dificuldade de articulação entre os diferentes ministérios e a consequente dificuldade em se romper com uma abordagem estritamente setorial, o entrevistado Z.L.S. nos conta das discussões e conferências realizadas abarcando diferentes temáticas.

Em termos de discussão e de abordagem sim, porque o Território da Cidadania patrocinou os principais temas através das Conferências Territoriais, de juventude, de ATER, de saúde, a questão da mulher nessa perspectiva da participação da mulher e do debate de gênero, então foi bastante participativo $[\ldots]$

[...] A outra política que ganhou muito corpo e discussão, foi muito animado o debate foi em relação ao PRONATEC Campo, foi um tema de bastante discussão, tirou-se equipes pedagógicas pra formular propostas de temas pra cursos, e isso também restringiu numa operacionalidade muito baixa, uma burocracia muito grande, teve-se proposta de romper com essas burocracias, propondo canais mais participativos, métodos pedagógicos mais voltados para a realidade, mas isso não passou das boas intenções não [...] 
[...] E num momento em que próprio governo que formula essa proposta, que é o governo do PT, na perspectiva de um projeto mais popular, numa ideia mais de converter as demandas sociais em programa sociais, que na verdade acabou sendo, a meu ver, uma espécie de institucionalização das organizações sociais, e o Estado se mostrou também na disputa desse Estado de um lado neodesenvolvimentista, mas também um Estado de natureza neoliberal, de um Estado mínimo $[\ldots]$

[...] Na verdade é uma correlação de forças políticas mesmo, as elites que detêm o poder econômico nesse país, e por consequência o poder político, ela se deu conta de que tinha que disputar mais-valia social de uma forma que essa mais-valia social que é o orçamento de todos seja convertido para a lógica do funcionamento do sistema de capitais, e não para o funcionamento de políticas sociais, algumas delas de caráter muito compensatório também... Se mostrou aí as políticas de inclusão produtiva e de inclusão de uma maneira geral, mas que não chegassem a ser inclusão do ponto de vista do empoderamento político (Z.L.S., Teodoro Sampaio, 16 de dezembro de 2016).

Notamos na fala do entrevistado a identificação da responsabilidade pela não efetivação de ações e redução no volume de recursos à correlação de forças disputando projetos, espaço e lutando para impor sua hegemonia dentro do aparelho do Estado. Esta compreensão se soma à discussão realizada ao longo deste trabalho sobre as relações de poder e os conflitos entre projetos de sociedade nos diferentes espaços e escalas de governo.

A correlação de forças no interior do Estado se reflete na orientação e na formulação das políticas públicas e, no caso deste estudo, no PTC. Assim, notamos que, refletindo orientações contidas na idealização do Programa e também sofrendo influência de grupos aos quais não interessa expor os conflitos inerentes ao território, o espaço de participação social do CODETER dificilmente trata da questão agrária no Pontal do Paranapanema, omitindo a conflitualidade e priorizando as discussões relativas à produção e comercialização que, embora sejam de grande importância, não descontroem as estruturas de poder no território.

\section{CONSIDERAÇÕES FINAIS}

Ao longo do percurso da pesquisa pudemos compreender como o, assim denominado, desenvolvimento territorial imposto à América Latina a partir de experiências externas, em que pese possibilitar a formação de importantes espaços de participação social de diferentes sujeitos, apresenta enormes limitações no que toca à proposta de se romper com o forte viés setorial no desenvolvimento de ações ou mesmo na formulação das chamadas políticas territoriais. Tal limitação fica evidente quando observamos que, mesmo com a propagandeada proposta de articulação interministerial contida na formulação do Programa Territórios da Cidadania, ainda permanece a dificuldade de integração das políticas públicas executadas pelas diferentes pastas. Apresentando a mesma dificuldade, na escala do Território, as discussões se pautam, predominantemente, em torno da elaboração e priorização de projetos destinados a disputar os recursos do PROINF. 
Ainda que atividades envolvendo outras temáticas, que não as relacionadas às cadeias produtivas agropecuárias, sejam desenvolvidas, na maioria dos casos, acabam circunscritas às discussões, conferências, seminários, entre outros eventos. Evidentemente, reconhecemos a importância deste tipo de atividade de formação e intercâmbio de experiências, entretanto, não nos foi possível observar concreta efetivação das propostas que emergem destas discussões.

A respeito do Colegiado de Desenvolvimento Territorial do Pontal do Paranapanema, pôde-se notar que, ainda que fortemente condicionado pela lógica setorial de discussão dos projetos voltados aos editais do PROINF, este espaço de participação tem proporcionado significativa organização social em torno de projetos de, ora maior, ora menor, interesse popular, se constituindo, assim, em mais um alvo de ataques do grupo que, atualmente, ocupa o poder executivo no país, para o qual é imperativo minar qualquer iniciativa de organização popular.

Ainda, o desenvolvimento da pesquisa nos permitiu notar a banalização no uso da categoria território, onde qualquer espaço físico, geograficamente delimitado, desde que sirva instrumentalmente aos interesses de Estado, passa a ser denominado território.

Nesta abordagem instrumental, "'questões territoriais' vêem, muitas vezes, sendo vulgarizadas e reduzidas, neste contexto de verdadeiro deslumbramento em que parece que 'tudo se tornou territorial'" (BRANDÃO, 2007, p. 12). Constata-se "o sentido oco que o território ganha, no interior da proposta de desenvolvimento territorial rural" (GÓMEZ, 2006, p. 399). Nota-se o quanto o território do desenvolvimento territorial se mostra esvaziado de conflitos, "coisificado" por uma abordagem que, ainda que leve em conta, em alguma literatura, os conflitos e contradições inerentes, em sua materialização, desconsidera-o "como construção social, como produto de conflitos e disputas em torno do espaço construído pela ação das classes sociais em seu processo de reprodução histórica" (BRANDÃO, 2007, p. 13-14).

Concluindo, consideramos que esta compreensão de que, por meio do território, pode-se promover uma harmonização de classes sociais antagônicas, num ambiente de consensos e coesão, na construção de um projeto de desenvolvimento comum que atenda aos diferentes interesses destas classes, dissimula os conflitos e as relações de poder contidas nestes espaços, servindo, desta forma, aos interesses dos grupos dominantes, a quem interessa manter os conflitos longe dos holofotes. Entendemos ser necessário revelar as relações de poder, explicitando as estratégias utilizadas por tais grupos para impor sua hegemonia. Trata-se de desmascarar o projeto hegemônico das elites e suas diferentes escalas de atuação, construindo, então, um projeto contra hegemônico e popular.

\section{REFERÊNCIAS}

BRANDÃO, C. Territórios com Classes Sociais, Conflitos, Decisão e Poder. In: ORTEGA, A. C.; ALMEIDA F., N. A. (Org.). Desenvolvimento territorial, segurança alimentar e economia solidária. Campinas: Editora Alínea, 2007. p. 1 - 25.

BRASIL. Ministério do Desenvolvimento Agrário. Secretaria de Desenvolvimento Territorial. Integração de políticas para reduzir desigualdades. Brasília, 2009. Disponível em: http://www.mda.gov.br/sitemda/sites/sitemda/files/ceazinepdf/ 3638134.pdf . Acesso em: 6 jun. 2016. 
BRASIL. Ministério do Desenvolvimento Agrário. Secretaria de Desenvolvimento Territorial. Caderno Territorial do Pontal do Paranapanema. Brasília, 2015. Disponível em:http://sit.mda.gov.br/download/caderno/caderno_territorial_ 073_Pontal\%20Do\%20Paranapanema\%20-\%20SP.pdf. Acesso em: 16 ago. 2016.

BRASIL. Ministério do Desenvolvimento Agrário. Secretaria de Desenvolvimento Territorial. Caderno Territorial do Pontal do Paranapanema. Brasília, 2015. Disponível em:http://sit.mda.gov.br/download/caderno/caderno_territorial_ 073_Pontal\%20Do\%20Paranapanema\%20-\%20SP.pdf. Acesso em: 16 ago. 2016.

BRASIL. Ministério do Desenvolvimento Agrário. Secretaria de Desenvolvimento Territorial. Plano Territorial de Desenvolvimento Rural Sustentável do Território do Pontal do Paranapanema. São Paulo, 2011.

BRASIL. Presidência da República. Casa Civil. Subchefia para Assuntos Jurídicos. DECRETO DE 25 DE FEVEREIRO DE 2008. Institui o Programa Territórios da Cidadania e dá outras providências. Brasília, DF, 2008. Disponível em: http://www.planalto.gov.br/ ccivil_03/_Ato2007-2010/2008/Dnn/Dnn11503.htm. Acesso em: 11 set. 2013.

DELGADO, N. G.; GRISA, C. Institucionalidades, governança e projetos territoriais na política de desenvolvimento rural no Brasil. In: MIRANDA, C.; TIBURCIO, B. (Org.). Políticas de desenvolvimento territorial e enfrentamento da pobreza rural no Brasil. Brasília: IICA, 2013. p. 239 - 287. (Série Desenvolvimento Rural Sustentável, v. 19). Disponível em: http://repiica.iica.int/docs/B3227p/B3227p.pdf. Acesso em: 6 out. 2016.

GÓMEZ, J. M. Desenvolvimento em (des)construção: narrativas escalares sobre desenvolvimento territorial rural. 2006. $438 \mathrm{f}$. Tese (Doutorado em Geografia). Faculdade de Ciências e Tecnologia, Universidade Estadual Paulista, Presidente Prudente, 2006. Disponível em: http://repositorio.unesp.br/bitstream/ handle/11449/105042/montenegrogomez_jr_dr_prud.pdf? sequence =1\&isAllowed =y. Acesso em: 05 jul. 2016.

SÃO PAULO. Secretaria da Justiça e da Defesa da Cidadania. Fundação Instituto de Terras do Estado de São Paulo. Fundação Itesp: sua história e realizações, evolução das políticas agrária e fundiária no estado de São Paulo. São Paulo, 2013. 